\title{
Factors Affecting Breast Feeding - A Comparison of Two British Military Hospitals
}

*Maj A J Lyon

MA, MRCP, RAMC

Senior Specialist Paediatrics

British Milifary Hospital, Rinteln

SUMMARY: The current infant feeding practices of $m$ others who were delivered in two military hospitals, in England and West Germany were reviewed. The expected social class differences were found, but even among the lower social classes more mothers than previously reported were breast feeding their babies for at least six weeks post partum.

Comparison of the mothers delivering in England with those in Germany gives some support to the view that antenatal influences were more important than postnatal education in determining if a mother would successfully breast feed. Parity, mode of delivery and length of stay in hospital had no effect on feeding. Maternal smoking was correlated with failure to maintain breast feeding, and as this association was found in all socioeconomic groups, it is suggested that smoking may have a direct effect on breast feeding.

\section{Introduction}

Despite increasing medical opinion in favour of breast feeding, surveys have shown that over the last ten years, newborn infants are mainly fed on formulated milks. A study in Newcastle in $1976^{1}$ reported that $30 \%$ of mothers were breast feeding on discharge from hospital, while in Liverpool $^{2}$ it was only $10 \%$. There is evidence that the prevalence of breast feeding is increasing ${ }^{3}$. In Oxford the proportion breast feeding on discharge increased from $37 \%$ in $1972 / 73^{4}$ to $52 \%$ in $1974 / 75^{\circ}$ with an increase in the length of time breast feeding was continued. A similar trend was reported in Harrow with a rise from $38 \%$ in 1972 to $69 \%$ in $1976^{6}$.

This study was carried out to determine current infant feeding practices in two British Military Hospitals; to compare mothers delivered in England and West Germany, and to consider some of the factors which may influence infant feeding.

\section{Method}

The data was collected in a three month period, in late 1981 in the Louise Margaret Military Hospital, Aldershot, England and over a similar period in early 1982 in the British Military Hospital Rinteln, West Germany. The former hospital delivers both service and local civilian mothers, while the latter admits only military dependants. The same protocol was used in each study.

\footnotetext{
${ }^{*}$ Now Hon Senior Registrar, Neonatal Unit $S t$ George's Hospital, Tooting, London.
}

Mothers were interviewed soon after delivery Choice of feeding method, maternal age, parity an husband's occupation or rank were noted. Smokin\& history was recorded, a mother being defined as smoker if she had smoked during pregnancy and continued to do so after delivery. Mode of deliverto birth weight, length of stay in hospital and feeding method on discharge were recorded from the notesDetails of feeding method at six weeks post partum were obtained either by telephone contact with the mother or from the health visitors.

Infants with problems affecting feeding, e.g. prematurity requiring tube feeding, were excluded.

The three groups of mothers, civilians (U.K.), military (U.K.), and military (Germany), were compared for maternal age, parity, smoking history, birth weight, length of stay in hospital and feeding history. The data was then regrouped into mothers breast feeding at delivery; at time of discharge from hospital and at six weeks post partum. These groups were compared, with those bottle feeding, for maternal age, parity, smoking history, birth weight, length of stay in hospital and socioeconomic class. $\mathrm{X}^{2}$ and Student's $t$ test were used for the statistical analyses.

Attempts were made to minimise any possible effects the study may have had on choice of feeding method. The proportion of mothers leaving each hospital fully breast feeding were similar before, during and after the study periods. Mothers were not aware that they would be contacted after discharge from hospital. 


\section{Results}

In England, 590 mothers were interviewed, 542 being included in the study (359 civilians and 183 service wives). In Germany, 327 mothers were included out of 345 interviewed.

Overall, $76 \%$ expressed a wish to breast feed, and, by the time of discharge $66 \%$ of all the mothers were fully breast feeding. Four hundred and sixty-five $(83 \%)$ of the 563 mothers discharged breast feeding were contacted at six weeks; 293 $(63 \%)$ were still fully breast feeding.

Table 1 compares the civilian and service mothers. The two groups of service wives were similar except for the longer stay in hospital of those delivered in Germany $(\mathbf{P}<0.02)$. This reflects the policy in military hospitals in Germany of not usually discharging mothers until five days post partum.

Civilian mothers were older $(\mathrm{P}<0.001)$, fewer smoked $(\mathrm{P}<0.001)$, and they were more likely to breast feed for at least six weeks $(P<0.0001)$. Table 2 shows that feeding history of officers wives was similar to that of social classes I and II the senior NCO's to class III and the other ranks to social classes IV and $V$. The differences between civilian and military mothers was probably due to the skew of the latter towards the lower social classes.

Table 3 shows the smoking history, delivery history, parity and length of stay in hospital of all the breast feeding mothers. Length of stay in hospital or mode of delivery did not significantly affect the choice of feeding method. Primips were more likely than multips to choose to breast feed $(P<0.01)$ but by six weeks, parity had no apparent effect on infant feeding. Mothers who smoked, delivered babies of lower mean birth weight $(3.25$ $\mathrm{Kg}$ ) when compared to those delivered to nonsmokers $(3.40 \mathrm{Kg})(\mathrm{P}<0.001)$. They were less likely than non smokers to choose to breast feed $(P<0.01)$ and by six weeks significantly more smokers had changed to formulated feeds $(P<0.01)$. The smoking and nonsmoking groups were similar for maternal age, parity and length of stay in hospital.

Table 4 shows the numbers of smokers and non smokers breast feeding, according to socioeconomic group.

\section{Discussion}

More than three quarters of the mothers in this study wanted to breast feed, and two thirds had achieved this by the time of discharge from hospital. The expected social class differences were found but even among classes IV and V nearly $60 \%$ were breast feeding on discharge and more than $50 \%$ of these were still fully breast feeding at six weeks. This figure is higher than reported in previous studies.
Surveys have shown that a mother's decision to breast feed is usually made long before delivery, $\mathbb{D}$ and can be even before pregnancy ${ }^{3},{ }^{7}$. Postnatal education will increase the numbers leaving hospitalo fully breast feeding but will not prevent a rapido change to bottle feeds after discharge ${ }^{4}{ }^{7}$. Although: advice and support in the postnatal period are im- $\stackrel{\vec{P}}{\rightarrow}$ portant in helping a mother maintain breast feeding, 0 it appears that the major influences must be exerted in the early antenatal period. Some support for $\frac{\bar{s}}{D}$ this is found in the comparison of the service $\mathbb{\Phi}$ mothers in England and Germany. The majority of the service wives living in Germany are youngs mothers who can be left isolated in a strange country. for long periods whilst their husbands are on exer- $\overrightarrow{\vec{\omega}}$ cise. They are separated from their extended families $\omega$ and the health visitor and other social services are limited compared to those available in England. There were no significant differences in antenatal? services between the two hospitals and it was expected that, because of the lack of support in the postnatal period, the mothers in Germany would $\phi_{e}^{c}$ less likely to maintain breast feeding. No differencess were found, however, in the number of service? wives still breast feeding at six weeks which su gests that postnatal influence may be of less imp\&्ष tance.

Significantly more primips than multips were breßs

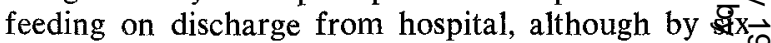
weeks the proportions were equal. Eighty-nine forro cent of the multips who were breast feeding at $\$$ weeks had successfully breast fed a previous che्fico whilst $85 \%$ of those who bottle fed from delive had never attempted to breast feed or had beeno unsuccessful with a previous child. Primips haveo not had the benefit of previous experience and sur- $\varrho$ veys have shown that they are more likely to breas $\overrightarrow{5}$ feed if friends or close relatives have breast fed 3 and if the mother herself was breast fed as a baby? Experiences with the first baby are obviously impor? tant, the longer the first baby is breast fed, the greater the chance of subsequent lactions being successful.

Mode of delivery was analysed as it is oftend still taught that Caesarian Section is a cause of failure to breast feed. This was not supported by this study.

Smokers were less likely to choose to breasid feed. This may reflect the personality of a woman who has continued to smoke during pregnancy deso pite repeated antenatal advice to the contrary. $B \mathbb{X}^{?}$ six weeks significantly more of the smokers has changed to bottle feeds and this trend was seen in each of the socioeconomic groups considered.

The possible effect of smoking on breast feeding is supported by the finding of lower circulating proN

\section{'}


Table I

Comparison of Mothers Delivered in England and Germany

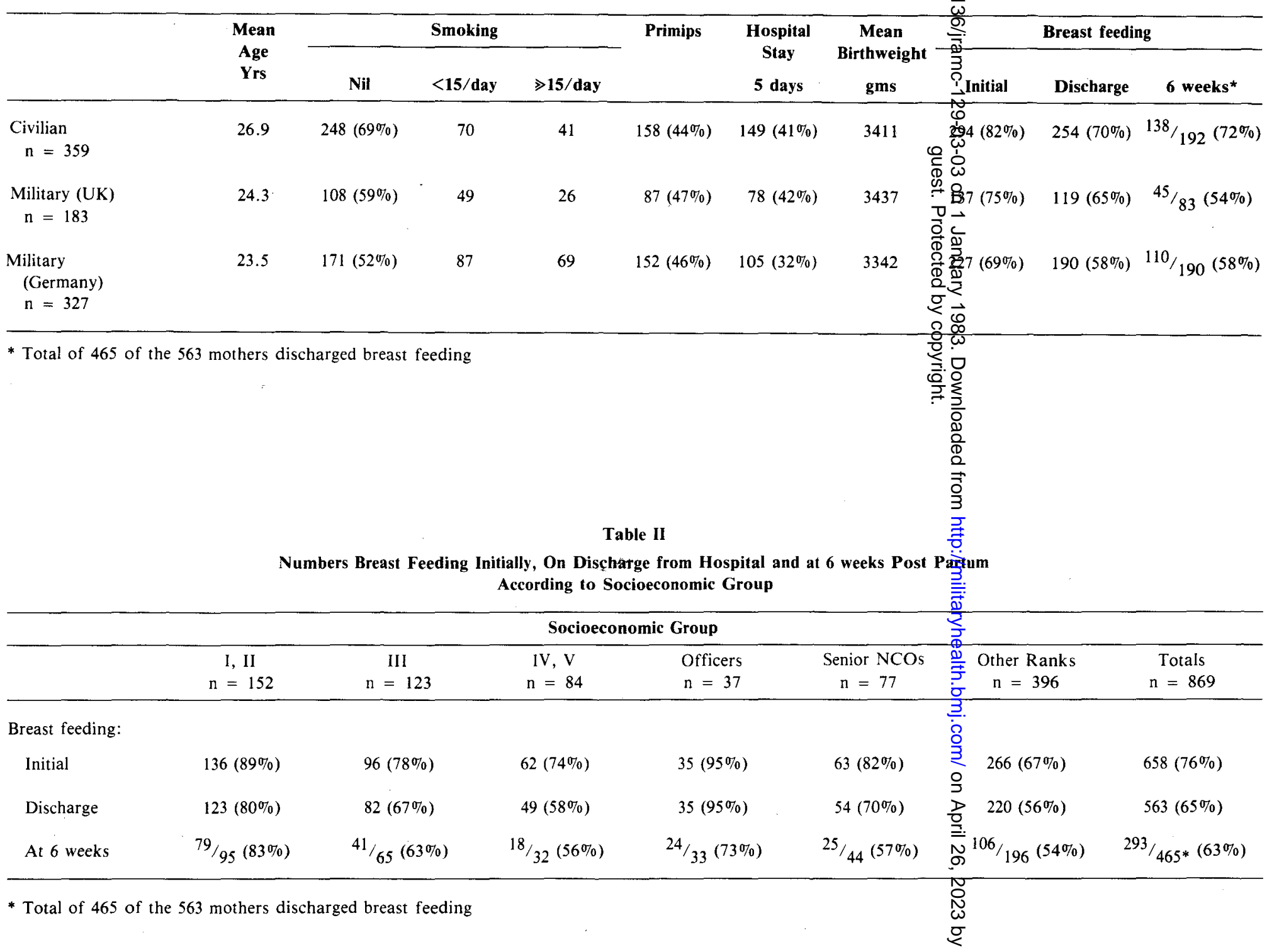


Table III

Numbers Breast Feeding Initially, On Discharge and at 6 Weeks Post Partum According to Parity, Delivery-History, Length of Stay in Hospital and Smoking Histor

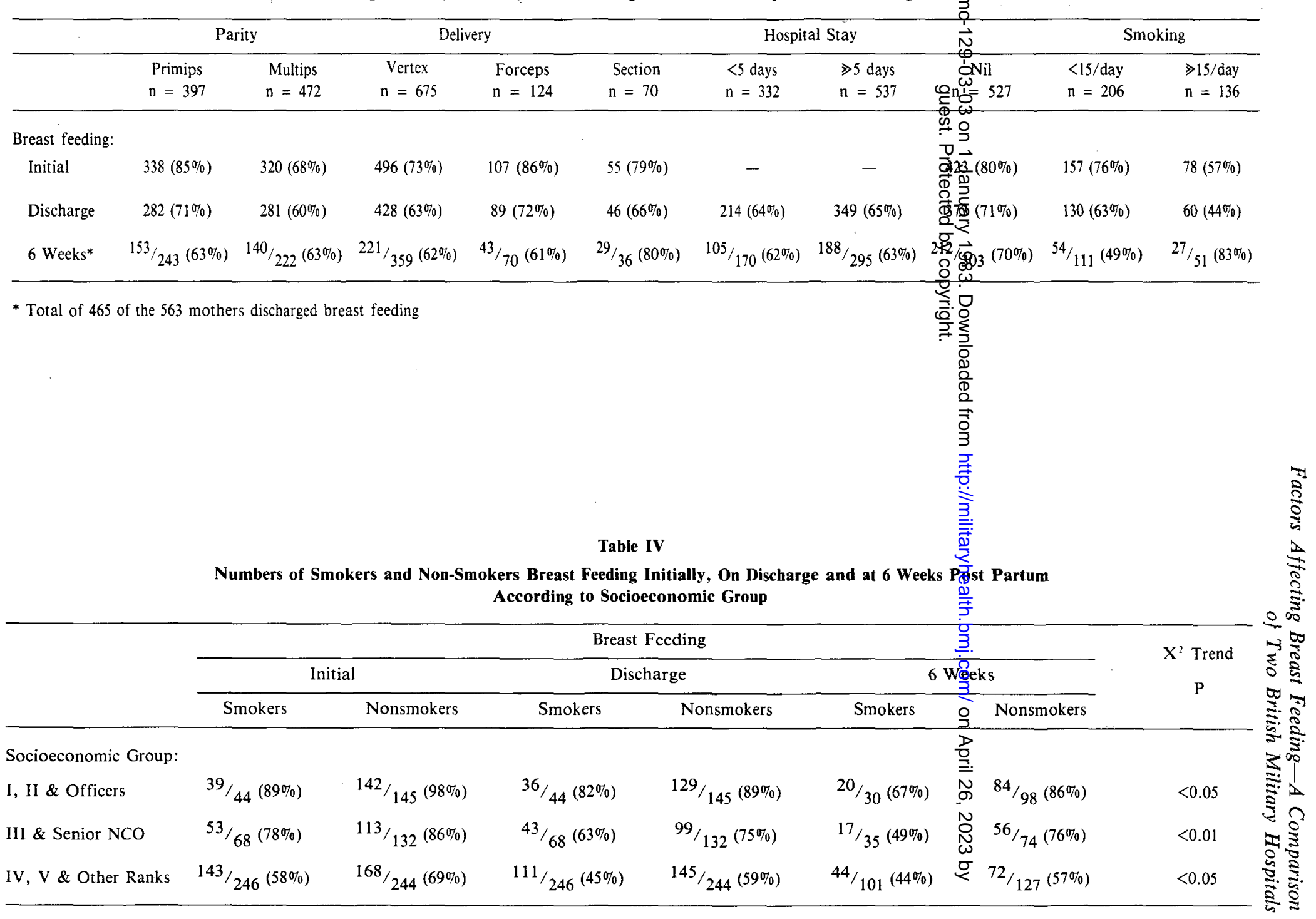


lactin levels in mothers who smoke ${ }^{8}$ and the observation that nicotine reduces milk production in lactating rats $^{9},{ }^{10}$. Nicotine is also excreted in breast milk ${ }^{11}$ but its effects on the breast fed infant are unknown. It may cause increased fretfulness which is interpreted as an unsettled baby due to underfeeding.

There is evidence that, in the mothers studied, more are breast feeding for up to six weeks post partum than previously reported.

Further improvement will depend on better antenatal education on feeding and general health measures, such as smoking in pregnancy. After delivery, the chances of successfully altering the way a mother has decided to feed her baby are slight. At this stage it would be more practical to concentrate efforts to help her succeed in her chosen method of feeding.

\section{Acknowledgements}

I thank the Health Visitors, Aldershot area, and the SSAFA sisters in the Rinteln area West Germany for their help in collecting information.

\section{REFERENCES}

1 BACON C J, WYLIE J M. Mothers' attitudes to infanto feeding at Newcastle General Hospital in summer 1975. Br Med .J 1976; 1: 308-309.

2 Davis J G. Encouraging breast feeding. Br Med 응 1976; 1: 1468 .

3 WHARTON B. A Quinquennium in infant feeding. $\overrightarrow{\vec{*}}$ Arch Dis Child 1982; 57: 895-897.

4 Sloper K, MCKean L, Baum I D. Factors influenc-으 ing breast feeding. Arch Dis Child 1975; 50:음 165-170.

5 SLOPER K, ELSDEN E, BAuM J D. Increasing breast feeding in a community. Arch Dis Child 1977; 52:응 700-702.

6 Coles E C, Valman H B. Breast feeding in $\overrightarrow{0}$ Harrow. Lancet 1976; 2: 583.

7 Eastham E, Smith D, Poole D, Neligan G. $\vec{\omega}$ Further decline of breast feeding. $B r$ Med $J$ 1976; 1: 305-307.

8 Nybo ANdersen A, Lund-Andersen C, Falck LARSEN J. et al. Suppressed prolactin, but normal neurophysin levels in cigarette smoking breast $\vec{\sim}$ feeding women. Clin Endocrinol 1982; 17:363-368.

9 Terkel J, Blake C A, Hoover V, SAwyer C H.O Pup survival and prolactin levels in nicotine treated lactating rats. Proc Soc Exp Biol Med 19;0; 143: 1131-1135.

10 BLAKE $C A$, SAWYer $C H$. Nicotine blocks tte suckling induced rise in circulating prolactin onc lactating rats. Science 1972; 177: 619-621.

11 Ferguson B B, Wilson D J, SchafFNer Determination of nicotine concentrations in human milk. Am J Dis Child 1976; 130: 837-839.

\section{RAMC Christmas Cards -1983}

The RAMC Christmas Card for 1983 is $6 " \mathrm{x} 4$ " folded card, die stamped with the Corps Crest on page $3 \frac{3}{5}$ with the Christmas Greetings.

The cover picture is a detail from the painting Adoration of the Kings, by Veronese, which is reproduced 3 by kind permission of the National Gallery.

Again this year, the sale of cards has been undertaken by the RAMC HISTORICAL MUSEUM, Keogh Barracks, Ash Vale, Hants GU12 5RQ, to whom all enquiries should be addressed. Each card is inserted in a plain envelope and the cost per card inclusive of postage (Home and Overseas) is 18 PENCE. POSTAGE OVERSEAS is by normal surface means.

The price of the cards and Overprinting is the same as last year.

\section{OVERPRINTING}

If a brief address is required to be printed on the greetings page (page 3) the Museum will arrange for음 this service with the printer. The following rates are notified:

UP TO 50 CARDS $-\ldots 4.50$.

Each additional Card- -2 pence.
Cash for overprinting to accompany the Order. OVERPRINTING ORDERS CANNOT BE ACCEPTED AFTER MONDAY, 5 DECEMBER, 1983. 